\title{
DEVELOPMENT OF LOW-COST \\ DIRECTIONALLY-SOLIDIFIED TURBINE BLADES
}

\author{
G. S. Hoppin, III, M. Fujii \\ AiResearch Manufacturing Co. of Arizona \\ A Division of The Garrett Corporation \\ L. W. Sink \\ Tiernay Manufacturing Co.*
}

A low-cost process for casting directionally-solidified (DS) turbine blades of high stress-rupture strength has been successfully developed. The process employs an exothermically heated mold to produce DS castings. Using this process, a newly designed solid blade for the high-pressure turbine of the Garrett TFE731-3 turbofan engine was cast in the Mar-M 247 and Mar-M 200+Hf alloys and engine-tested. The solid DS blade replaced a cooled, conventionally cast IN 100 blade. An engine test in this research and development program showed a 2.4-percent reduction in takeoff specific fuel consumption. An estimated 40-percent reduction in finished turbine blade cost was realized. As a result, the new DS Mar-M 247 blade has been selected for production in the TFE731-B-100, an advanced version of the TFE731-3 engine.

*Formerly with AiResearch Manufacturing Co. of Arizona

A Division of The Garrett Corporation. 


\section{BACKGROUND TECHNOLOGY}

The development of sophisticated techniques for producing DS turbine airfoils for large aircraft engines has been extensively documented by Pratt and Whitney Aircraft scientists and engineers(1). The most widely used production method in this country for producing DS airfoils is the so-called "withdrawal" process, wherein blades are cast in a ceramic mold against a water-cooled copper chill, the mold then being mechanically withdrawn from a vacuum furnace at a precisely controlled rate. This technique has received so much emphasis that it is not generally realized that the first work done in this country on DS nickel alloys (2) was done by General Electric scientists using an exothermically heated mold. Later work on exothermic DS at TRW led to the 1969 patent of Chandley (3). More recently, the process was revived with considerably greater sophistication by Jetshapes, Inc. Cooperative work between Jetshapes and AiResearch led to the realization that the exothermic DS process offered the promise of simultaneously reducing the turbine blade cost and also reducing the fuel consumption of the TFE731-3 turbofan engine -- a widely used general aviation powerplant. This technology was successfully reduced to practice as the initial AiResearch project in the NASA-Lewis Research Center Materials in Advanced Turbine Engines (MATE) Program.

\section{EXOTHERMIC DS CASTING PROCESS DEVELOPMENT}

A cross-section of a typical 25 -centimeter base diameter mold for casting turbine blades by the exothermic DS process is shown in Figure 1. The mold is initially prepared by dip-coating a wax

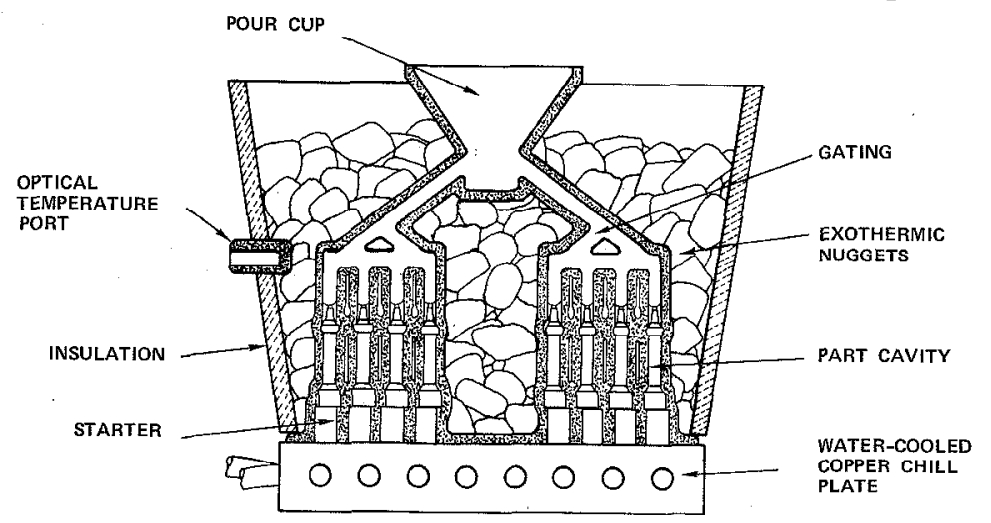

Figure 1. Schematic Cross-Section of Mold and Chill for Exothermic DS Process. 
assembly resting on an aluminum plate with a typical investment casting ceramic mold material. Best foundry results were obtained by using a mold facecoat of colloidal alumina backed up by multiple dips of zirconium aluminum silicate. After dipping, air-drying and dewaxing, the mold is conventionally fired. It is then placed within an outer ceramic sleeve and filled with exothermic pellets made by press-densification of high-purity pulverized aluminum and iron oxide. The assembly is then furnace-ignited within a gas-fired box furnace preheated to and held at $1093^{\circ} \mathrm{C}\left(2000^{\circ} \mathrm{F}\right)$ with an oxidizing atmosphere present. Ignition of the exothermic pellets to create the classic thermit reaction occurs within 5 to 7 minutes. The reaction proceeds to completion after a total time of 15 minutes in the $1093^{\circ} \mathrm{C}$ furnace. The heated mold is transferred to a stationary water-cooled copper chill in the casting chamber of a vacuum casting unit. The mold temperature prior to pouring is in the $1590-1650^{\circ} \mathrm{C}$ $\left(2900-3000^{\circ} \mathrm{F}\right)$ range. The alloys poured are preheated to $1482^{\circ} \mathrm{C}$ $\left(2700^{\circ} \mathrm{F}\right)$ a superheat of about $190^{\circ} \mathrm{C}\left(375^{\circ} \mathrm{F}\right)$ above their liquidus temperatures.

After the mold is poured, it is initially completely full of liquid metal, since the mold temperature is well above the liquidus temperature of nickel base superalloys. Solidification initiates at the circular "starters" that contact the chill. A sorting out process to select the fastest growing (001) oriented grains begins instantaneously and is completed about $6.4 \mathrm{~mm}$ above the chill plate. Parallel (001)-oriented grains then solidify into the blade cavities in the steep thermal gradient present. Fifteen minutes after casting, the molten metal completely solidifies and the mold is removed from the vacuum chamber. After removal from the mold, the blades are roughly macroetched for grain structure, solution heat-treated, cleaned, inspected and ultimately finish-processed into parts for engine assembly.

The total technology developed that resulted in the qualification of DS turbine blades for the TFE731 engine involved a blade redesign for improved aerodynamic performance and stress distribution, as well as the casting process development. Figure 2 shows a comparison of the prior air-cooled IN100 blade and the new solid DS blade, which has been heavily macroetched to show the typical columnar grain structure.

The initial casting development work performed to define the exothermic casting process was done with one preferred alloy, Mar-M 247. After the casting process was established, the response of three other alloys to this process was also studied. 


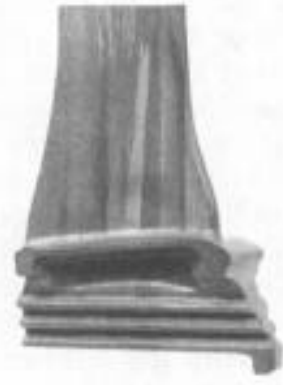

A

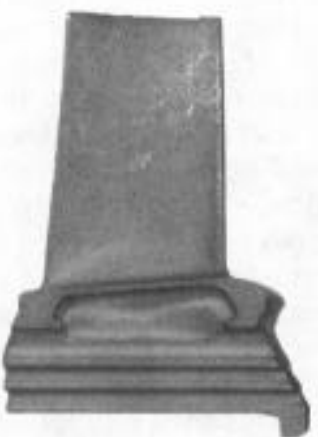

B

Figure 2. (A) Cooled IN 100 Turbine Blade for TFE731-3 and

(B) Uncooled DS Mar-M 247 Blade for TFE731-3B-100.

A solution heat-treatment study was performed to maximize the stress-rupture properties of DS Mar-M 247. The three other alloys studied in the program were Mar-M 200+Hf, IN792+Hf, and NASA-TRW-R. The nominal chemical compositions of these alloys and IN100 are listed in Table I. Mar-M 200+Hf was a useful baseline alloy in the program, since it is the production military and production DS airfoil alloy extensively used by Pratt and Whitney Aircraft. IN792 $+\mathrm{Hf}$ is a somewhat weaker, but more corrosion-resistant alloy than Mar-M 247 or Mar-M 200+Hf. The NASA-TRW-R alloy was of interest, due to its stress-rupture strength.

TABLE I. Nominal Chemical Compositions of Turbine Blade Alloys.

\begin{tabular}{|c|c|c|c|c|c|c|c|c|c|c|c|c|c|c|}
\hline \multirow[b]{2}{*}{ Al.LOY } & \multicolumn{14}{|c|}{ WEACHT (PEHCENT) } \\
\hline & $\mathrm{Ni}$ & $\mathrm{Cr}$ & $C_{0}$ & Mo & w & $T_{4}$ & $c b$ & Al & $\pi$ & C & B & $\mathrm{zr}$ & HI & $v$ \\
\hline MAR-M 24T & 50 & 8.4 & 10.0 & 0,6 & 10.0 & 3.0 & $\cdots$ & 5.5 & 1.0 & 0.15 & 9.015 & 0.06 & 1.4 & $\cdots$ \\
\hline MART-M 200 + TIE & 59.5 & 8.5 & 10.0 & $\cdots$ & 12.0 & $\cdots$ & 1.0 & 5.0 & 2.0 & 0.15 & 0.015 & 0.06 & 2.0 & $\cdots$ \\
\hline w5ร $52+$ Hr & 60 & 12.4 & 9.0 & 1.8 & 4.0 & 3.9 & $\cdots$ & 3.3 & 4.9 & 0.09 & 0.015 & 6.to & 1.0 & + \\
\hline NASA-TR W-R & 62 & 8.0 & 7.8 & 3.6 & 4.0 & 7.0 & 0.3 & 5.5 & 1.0 & 0.08 & B.915 & 0.12 & 1.0 & $\cdots$ \\
\hline IN 100 & 60 & 10.0 & 15.6 & 3.0 & $\cdots$ & $\cdots$ & $m$ & 5.5 & 4.T & 0.13 & 0.014 & 0.06 & $\cdots$ & 1.0 \\
\hline
\end{tabular}


G. S. Hoppin, M. Fujii, L. W. Sink / 229
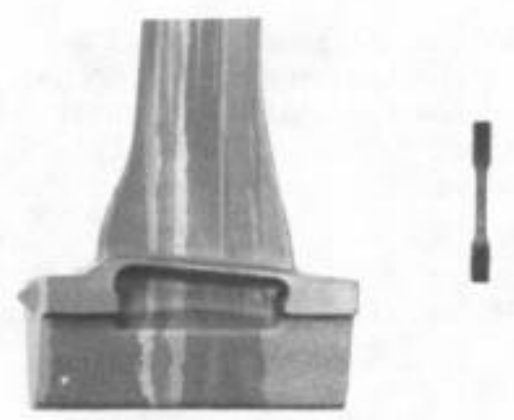

Figure 3. Location of Tensile and Stress-Rupture Test Specimens Machined from TFE731-3-100 Turbine Blades (Bar Gauge Diameter $=1.78 \mathrm{~mm}$.).

As development work proceeded, techniques were developed by the Joliet Metallurgical Laboratory to machine small test bars from actual TFE731-3 blades in both longitudinal and transverse orientations. Two of the $1.78-\mathrm{mm}$ gauge diameter bars and the areas from which they were machined from a blade are shown in Figure 3.

The DS casting process established for Mar-M 247 was found to work well with the other three alloys. Before major mechanical property testing was done, a heat-treatment study was performed to establish a common process for the four alloys. The following process was used to heat-treat the alloys:

- Solution-treat at $1232^{\circ} \mathrm{C}\left(2250^{\circ} \mathrm{F}\right)$ for 2 hours in vacuo followed by an argon gas fan quench

- Simulated aluminide coating cycle at $982^{\circ} \mathrm{C}\left(1800^{\circ} \mathrm{F}\right)$ for 5 hours

- Final age for 20 hours at $871^{\circ} \mathrm{C}\left(1600^{\circ} \mathrm{F}\right)$.

This process produced a small, but innocuous amount of incipient melting in the alloys, and resulted in the precipitation of a maximum amount of fine gamma grime $\left(\gamma^{\prime}\right)$, which has been shown to maximize creep-rupture streng th ${ }^{(4)}$.

The properties of greatest interest for screening the alloys were the $760^{\circ} \mathrm{C}\left(1400^{\circ} \mathrm{F}\right)$ tensile properties, and the $982^{\circ} \mathrm{C}\left(1800^{\circ} \mathrm{F}\right)$, stress-rupture properties. The tensile properties are of concern for the fir-tree attachment region of the blade, while adequate stressrupture strength is needed for the airfoil. The $760^{\circ} \mathrm{C}$ tensile 
properties obtained on the four DS alloys are summarized in Table II and compared to similar properties of IN100. The best balance of tensile properties were exhibited by Mar-M 247. Transverse tensile properties were not determined on IN792+Hf, since that alloy had earlier been dropped from consideration due to lack of adequate

TABLE II. Average $760^{\circ} \mathrm{C}\left(1400^{\circ} \mathrm{F}\right)$ Tensile Properties of DS Turbine Blades. (Four Alloys and Equiaxed IN100)

\begin{tabular}{|c|c|c|c|c|c|c|c|c|c|c|}
\hline \multirow{2}{*}{$\frac{\text { Alloy }}{\text { (Orientation) }}$} & \multicolumn{2}{|c|}{$\begin{array}{c}\text { Ultimate Tensile } \\
\text { Strength } \\
\text { MPa (KSI) }\end{array}$} & \multicolumn{4}{|c|}{$\begin{array}{c}0.2 \% \\
\text { Yield Strength } \\
\text { MPa (KSI) }\end{array}$} & \multicolumn{2}{|c|}{$\begin{array}{c}\text { Elongation } \\
\text { (\%) }\end{array}$} & \multicolumn{2}{|c|}{$\begin{array}{c}\text { Reduction } \\
\text { in Area } \\
(96)\end{array}$} \\
\hline & $L^{*}$ & $\mathrm{~T}^{* *}$ & & $\mathrm{~L}$ & & $\mathbf{T}$ & $\mathrm{L}$ & $\mathrm{T}$ & $\mathbf{L}$ & $\mathbf{T}$ \\
\hline MAR-M 247 & $1165(169)$ & $934(135)$ & 970 & $(141)$ & 834 & (121) & 4.9 & 6.0 & 13.9 & 12.2 \\
\hline MAR-M $200+H F$ & $1158(168)$ & $842(122)$ & 1033 & $(150)$ & 754 & $(109)$ & 4.3 & 3.4 & 12.7 & 7.3 \\
\hline IN $792+\mathrm{Hf}$ & $1129(164)$ & ----- & 791 & (115) & -+- & $\cdots$ & 12.8 & --- & 30.7 & $-\cdots$ \\
\hline NASA-TR W-R & $1177(171)$ & $843(122)$ & $(924)$ & $(134)$ & 801 & (116) & 5.4 & 4.0 & 13.1 & 9.4 \\
\hline $\begin{array}{l}\text { (EQUIA XED } \\
\text { IN 100) }\end{array}$ & $1069(155)$ & ----- & 862 & (125) & --- & --- & 6.5 & -- & --- & --- \\
\hline
\end{tabular}

* L = LONGIT UDINAL; **T = TRANSVERSE

$982^{\circ} \mathrm{C}\left(1800^{\circ} \mathrm{F}\right)$ stress-rupture streng th. The stress-rupture lives of the other three alloys at this temperature and $207 \mathrm{MPa}$ are shown in Table III. The Mar-M 247 alloy again shows a strength advantage over the other alloys.

TABLE III. Average Stress-Rupture Life at $982^{\circ} \mathrm{C} / 207 \mathrm{MPa}\left(1800^{\circ} \mathrm{F}\right.$. /30KSI) for Longitudinal specimens Machined from DS Turbine Blades Cast in Three Alloys.

$\begin{array}{lc}\frac{\text { ALLOY }}{\text { MAR-M 247 }} & \text { LIFE (HRS) } \\ \text { MAR-M 200+Hf } & 91.2 \\ \text { NASA-TRW-R } & 70.5 \\ & 64.5\end{array}$

Prior to the engine testing, the longitudinal and transverse stress-rupture properties of Mar-M 247 were determined over a temperature range of $760-1038^{\circ} \mathrm{C}\left(1400-1900^{\circ} \mathrm{F}\right)$ for times up to 1678 hours. The data generated was mathematically analyzed and is presented in Figure 4 as a plot of stress versus the Larson-Miller time and temperature parameter and is compared both to equiaxed IN 100 and the original (longitudinal orientation) strength goal of the program. Improvements in casting quality and heat-treatment practice allowed the goal to be substantially exceeded. 


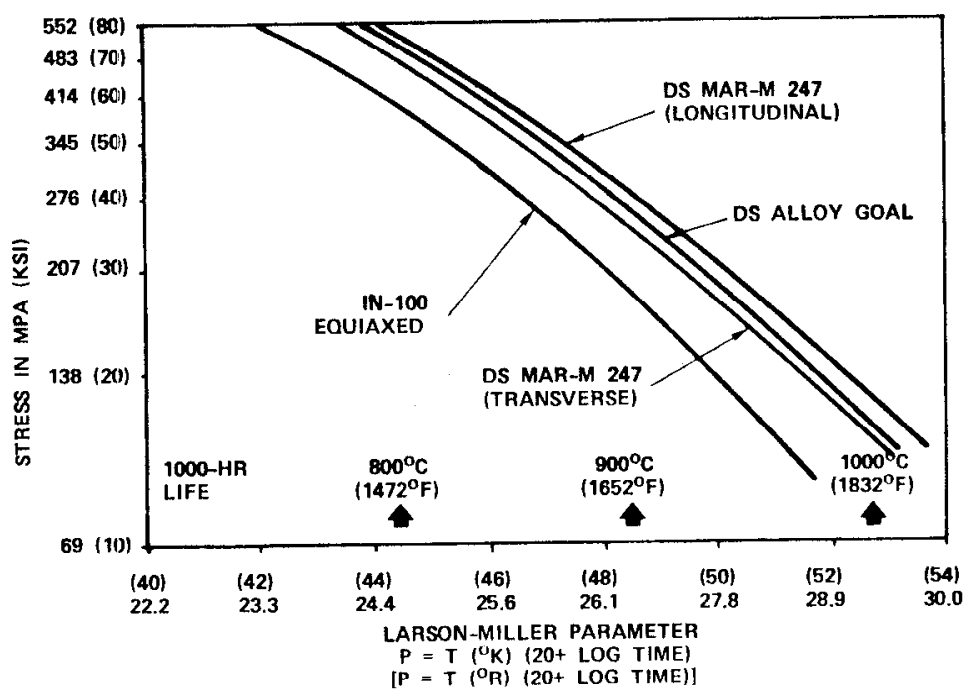

Figure 4. Comparative Stress-Rupture of Equiaxed IN 100 and Strengths Achieved for DS Mar-M 247 Vs. DS Alloy Goal.

\section{ENGINE TEST BLADE MANUFACTURE}

The original program plan was to manufacture and engine test a blade mix of 50-percent Mar-M 247 and 25-percent each of Mar-M 200+Hf and NASA-TRW-R. This plan was changed once the casting of the blades for engine test began. It proved impossible to cast the final engine test configuration blade of the NASA-TRW-R alloy without hot-tear cracking occurring in the thin platform below the airfoil on over 80 -percent of the blades. This alloy was dropped from the engine test plan.

The engine test blade casting continued with the two Martin Metals alloys. A total of 300 blades were cast of Mar-M 247 and 165 cast of Mar-M 200+Hf. Overall casting yields were about 60 -percent for Mar-M 247, and 45-percent for the older alloy. The reasons for the differing yields were related to the higher hafnium content of the older alloy. This resulted in metal-mold reactions that formed hafnia, which could cause either X-ray rejections for high-density inclusions or fluorescent penetrant rejections for surface-entrapped particles.

Manufacture of the engine test blades involved casting, solution heat treatment, finish machining, and finally, coating application and final aging treatment. The finished blades were then delivered to AiResearch for assembly in a modified TFE731-3 engine and enginetested. 


\section{ENGINE TESTS}

The initial engine test performed on the DS blades consisted of two back-to-back performance tests followed by three 50-hour endurance tests. The initial performance test was run with the engine in a standard production configuration (i.e., with air-cooled IN100 turbine blades). The second test was run with a set of DS blades and modified turbine hardware. The performance tests showed that the DS blades reduced engine specific fuel consumption (SFC) by 2.4 percent at sea-level, take-off conditions. Of the performance improvement, 1.3 percent was attributed to the elimination of blade cooling air and 1.1 percent to the more efficient aerodynamic design of the solid DS blade. The 2.4-percent efficiency improvement exceeded the original NASA-MATE project goal of 1.7 percent.

Following the performance runs, the first 50-hour test performed was a high-cycle-fatigue evaluation. The engine was stepped from idle to maximum continuous power in 14 increments of continually advanced power settings, with 90 minutes typical operation at each power setting. It was then held at maximum continuous power for 3 hours and again stepped down to idle in 14 power setting increments. The second 50-hour test was basically a stress-rupture test, where the engine was held at maximum continuous power for 50 hours. The third 50 -hour test was a low-cycle-fatigue cycling test. The engine was accelerated to maximum continuous power from idle, held at maximum power for 10 minutes, decelerated to idle, held for 10 minutes, and again accelerated to maximum continuous power.

At the conclusion of each 50-hour test, some blades of each alloy were removed for examination and new blades substituted. At the conclusion of the 150 hours of testing, about half the blades had the full 150 hours of testing, while some blades had 50 hours, and others, 100 hours. Both non-destructive and destructive tests performed on the engine tested blades indicated no distress resulting from engine testing. Microstructural examination was performed to check for blade coating thickness which was within the specified range of $0.025-0.030 \mathrm{~mm}(0.001-0.0012$ inch). No change in blade microstructures occurred as a result of this engine testing.

\section{CONCLUSIONS}

The success of this engine testing led to the decision to employ the solid DS blade in a new version of the basic engine, and designated the TFE731-3B-100. This engine will be used in advanced versions of general aviation aircraft. Garrett-funded engine testing of DS blades for engine certification purposes has continued since the 
conclusions of the NASA-funded program. As of January 15, 1980, a total of 686 hours of test time on the TFE731-3B-100 DS blade had been accumulated on two factory test engines and four flight test engines.

Cost -- as well as performance -- was one of the motivations to qualify the solid DS blade in the TFE731-3. At the conclusion of the NASA-funded contract, an analysis was made comparing the projected production cost of the DS blade, to the air-cooled IN100 blade (Figure 5). As indicated, a 40-percent cost savings by use of the DS blade was projected. Experience gained since the completion of the NASA-MATE project indicates that this projection is valid.

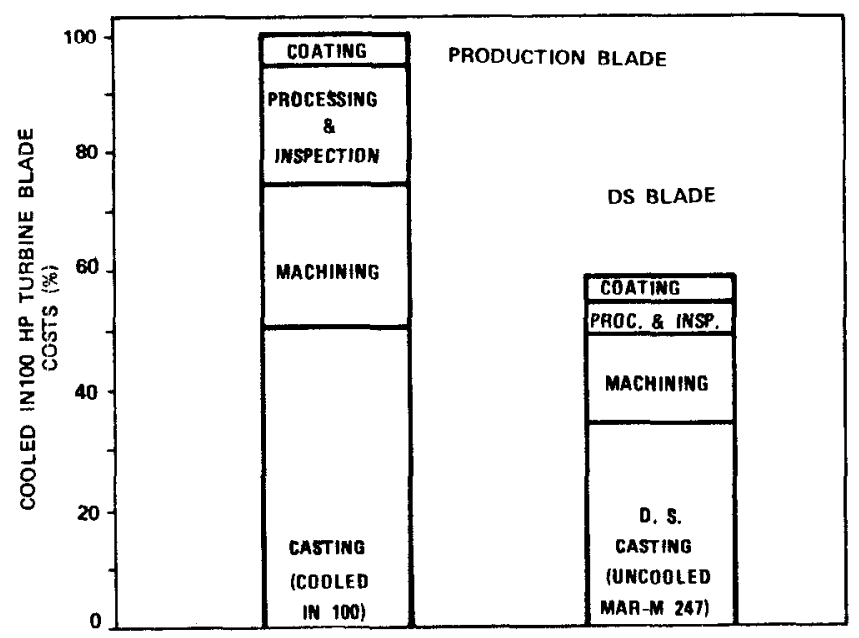

Figure 5. Comparative Production Costs of Air-Cooled Equiaxed IN 100 and Uncooled DS Mar-M 247 High-Pressure Turbine Blades for the TFE731-3.

In summary, this research and devclopment program shows that a solid DS blade of Mar-M 247 made by the exothermic DS process could replace an air-cooled IN 100 blade in the high-pressure turbine of the Garrett TFE731-3 turbofan engine. The incorporation of the DS blade has the potential for improving engine SFC by 2.4 percent, while reducing turbine blade costs by 40 percent. 


\section{ACKNOW LEDGEMENTS}

The technical assistance and advice of Dr. R. L. Dreshfield of the NASA-Lewis Research Center and Mr. C. M. Phipps, Jr. of Jetshapes materially assisted in the success of the development program described.

\section{REFERENCES}

(1) J. S. Erickson, C. P. Sullivan, and F. L. VerSnyder, "Modern Processing Methods and Investment Casting of the Superalloy Family," pp. 315-340 in High-Temperature Materials in Gas Turbines, edited by Sahm and Speidel, Elsevier, 1974.

(2) F. L. VerSnyder and R. W. Guard, "Directional Grain Structures for High-Temperature Strength," Trans. ASM, 52 (1960) pp. 485-493.

(3) G. D. Chandley, "Method and Apparatus for Improving Grain Structures and Soundness of Castings," U.S. Patent 3,441,078, April 29, 1969.

(4) J. J. Jackson et al, "The Effects of Volume Percent of Fine $\gamma$ ' on CREEP in DS Mar-M $200+\mathrm{Hf}, "$ PP. 1615-1620, Metallurgical Transactions A, October 1977. 